\title{
As exigências da política nacional de Habitação e a sua operacionalidade na cidade de Cajazeiras - PB
}

The requirements of the national housing policy and its operationality in the city of Cajazeiras $-P B$

\author{
Sharlene Dantas Moraes* \\ Lindalva Alves Cruz* \\ Andréia Braga Oliveira ${ }^{* * *}$
}

\section{Resumo}

Este artigo é parte do trabalho de conclusão do curso de Serviço Social na Faculdade Santa Maria, Cajazeiras - PB no ano de 2017. Aqui, foi analisado a operacionalidade da Política Nacional de Habitação (PNH) no Conjunto Habitacional Recreio na cidade de Cajazeiras na Paraíba, e se a construção contemplou as exigências da produção de habitação de interesse social, sendo esse direcionado para a população de baixa renda. Enfatizou-se a implementação da Política Nacional de Habitação (2004) através do programa Minha Casa Minha Vida, priorizando o subsistema de interesse social. Os procedimentos metodológicos foram de caráter qualitativo, com pesquisa documental e de campo. Para coleta dos dados, adotou-se a observação em campo, e a entrevista. Os resultados revelaram que a operacionalidade da Política Nacional de Habitação (PNH) aconteceu de forma conflituosa, pois foram identificadas falhas no processo que envolveu o Conjunto Habitacional Recreio referente aos critérios de qualidade e conforto das famílias, bem como a não concessão da documentação definitiva, além de infraestrutura incompleta. Apesar disso, é inquestionável a importância dessa política para o acesso à moradia. Hoje, diferente dos últimos governos, enfrenta-se o verdadeiro desmonte da Política Nacional de habitação.

Palavras-chave: Política Nacional de Habitação. Moradia.

\begin{abstract}
This article is part of the course completion work of social work course at Faculdade Santa Maria, Cajazeiras (PB), in the year 2017. Here, we analyze the operation of the National Housing Policy (NHP) in the Conjunto Habitacional Recreio of the city of Cajazeiras (PB). We aim to understand if the construction of the cited Set contemplated the requirements of the production of housing of social interest, which is for the low-income population. We emphasize the implementation of the new National Housing Policy and the Minha Casa Minha Vida program, prioritizing the subsystem of social interest. The methodological procedures were qualitative. For the collection, we adopted field observation, interview and documentary research. The results revealed that the operation of the National Housing Policy (NHP) happened in a conflictive way, since we identified flaws in the process involving the Conjunto Habitacional Recreio referring to the quality and comfort criteria of the families, as well as the non-concession of the definitive documentation and incomplete infrastructure. Despite this, the importance of this policy for access to housing is unquestionable. Today, unlike the last governments, we face the real destruction of the National housing policy.

\footnotetext{
* Graduada em Serviço Social pela Faculdade Santa Maria, Cajazeiras, PB. Pesquisadora do grupo GEPEGESP/FSM.

** Dra. Em Sociologia pela UFPE; professora da Faculdade Santa Maria, Cajazeiras, PB, líder institucional do Grupo de Estudo Pesquisa e Extensão em Gênero e Economia Solidária e Cidadania (GEPEGESC/ FSM).

${ }^{* * *}$ Coordenadora do Curso de Serviço Social da Faculdade Santa Maria, Cajazeiras, PB.
} 
Keywords: National Housing Policy. Housing. Operability.

\section{Introdução}

A aquisição de moradia sempre foi o grande anseio das famílias de baixa renda do Brasil. No início do século XX, já existia movimentação dos governos no sentido de atenuar a voracidade do capitalismo, que já expunha a disparidade de classes. À medida que a população ia aglomerando-se nos centros urbanos, diferentes tentativas, buscavam atender à necessidade de parcela dos mais pobres, iniciativas essas, como incentivos fiscais às empresas que construíssem casas populares, como também a retirada de alguns impostos. $\mathrm{Na}$ atualidade, o déficit habitacional continua um dos maiores problemas: mais de 6 milhões de famílias não têm onde morar - a maioria constituída por grupos familiares sem renda ou de baixíssimo poder aquisitivo (BRASIL, 2011).

Ainda no século XX, com a Declaração Universal dos Direitos Humanos, moradia digna passou a ser um direito de cada cidadão. No Brasil, a Constituição Federal de 1988, ratificou esse direito, mas o direito a moradia só passa a ser reconhecido como direito fundamental com a Emenda Constitucional 26/2000. Contudo, só no novo milênio, conhecesse a Política Nacional de Habitação. Assim, foi reconhecido a moradia como direito básico e constitucional de todos os cidadãos; logo, cabe ao Estado garanti-lo por meio de políticas públicas direcionadas às pessoas em situação de vulnerabilidade social.

Em 2009, ainda no mandato do presidente Luís Inácio Lula da Silva, deu-se início ao Programa Minha Casa Minha Vida (PMCMV), é importante demarcar aqui que o programa nasce no PAC - Programa de Aceleração do Crescimento, criado de 27 de janeiro de 2007, por meio de decreto e com intuito de viabilizar um novo modelo de gestão, planejamento e execução dos investimentos públicos, estão entre os objetivos do PAC, está estimular o crédito e o financiamento, modernizar a infraestrutura e elevar a qualidade de vida da população. Para Veras (2014) se trata de um programa voltado para a população mais pobre, que se destina a diminuir consideravelmente a falta de moradia. Propõe subsidiar a aquisição da casa própria para famílias com renda de até 1,6 mil reais e ainda facilitar as condições de acesso ao imóvel para as famílias com renda de até 5 mil reais.

As moradias para o primeiro grupo são famílias com renda de até 1,6 mil reais, denominadas de interesse social a seleção dos beneficiários é de responsabilidade das prefeituras e a operacionalização do programa é feita pela Caixa Econômica Federal (CEF). As 
moradias para o segundo grupo são denominadas habitação de mercado, as famílias com renda de $\mathrm{R} \$ 1.601,00$ até $\mathrm{R} \$ 3.275,00$ e o terceiro grupo as famílias com renda de $\mathrm{R} \$$ 3.275,00 até 5 mil reais. O governo Federal também define um teto mínimo para a comercialização das unidades, levando em consideração as características por cidade e região, e é a faixa de renda das famílias que defere o subsídio de cada beneficiário do programa.

Destarte, este artigo retrata o Conjunto Habitacional Recreio construído no ano de 2004, constituído por 100 unidades residenciais, situado no município de Cajazeiras, no bairro Pio X, zona norte da cidade, no estado da Paraíba. Segundo a prefeitura, ele foi construído para as famílias de baixa renda em conformidade com a orientação da Política Nacional de Habitação (PNH) e com o subsídio de habitação de interesse social.

Portanto o objetivo desse artigo foi analisar a operacionalização da construção do conjunto supracitado, no intuito de verificar se as execuções coadunaram com as diretrizes da $\mathrm{PNH}$, que têm como direcionamento o desenvolvimento institucional, a mobilização de recursos, a identificação da demanda e gestão de subsídios, a qualidade e produtividade habitacional, o sistema de informação, avaliação e monitoramento da habitação, a urbanização de assentamentos precários e a produção da habitação. Mas, o principal instrumento da PNH é o que propõe a participação democrática e a integração dos três níveis de governo, com também o envolvimento dos agentes públicos e privados. Bem como de entender se os critérios de seleção, dos beneficiários estavam conforme os estabelecidos pela $\mathrm{PNH}$, ou seja, pertencer ao grupo da população de baixa renda, na qual se concentra a maior parte do déficit habitacional do Brasil. Contribuíram principalmente para esse estudo os autores Bonduki (2008), Santos e Duarte (2010) e Veras (2014), porque têm a concepção de que a ausência de moradias para os trabalhadores se origina na natureza do capitalismo: exploração do trabalho (MARX apud VERAS, 2014).

Quanto à metodologia recorreu-se à de cunho qualitativo, considerando o tema para investigação e os objetivos da pesquisa. A apreensão dos dados foi desenvolvida de forma a associar diferentes instrumentos, como a entrevista semiestruturada e as pesquisas documental e bibliográfica. Em relação à mostra populacional, utilizou-se $10 \%$ das famílias contempladas pelo programa, que propôs subsidiar a aquisição da casa própria para famílias de baixa renda. Nessa amostra, foram incluídos apenas beneficiários voluntários resultantes de uma seleção aleatória durante visitas ao conjunto supracitado. 
Os resultados apontaram distância significativa entre a correta aplicação da PHN e a forma de executada no EMPREENDIMENTO em foco.

\section{A Nova Política Nacional de Habitação}

Com a Declaração Universal dos Direitos Humanos em 1948, ficou assegurada a moradia como condição indispensável para a dignidade do ser humano. No Brasil, a Constituição Federal de 1988, em seu art. 60, apresenta a seguinte declaração:

\footnotetext{
São direitos sociais a educação, a saúde, a alimentação, o trabalho, a moradia, o transporte, o lazer, a segurança, a previdência social, a proteção à maternidade e à infância, a assistência aos desamparados, na forma desta Constituição (BRASIL, 1988).
}

Assim, a moradia é um direito constitucional para todos, não apenas para uma parcela da população que vive nos centros urbanos. Esse direito, como os demais, deve ser assegurado pelo Estado por meio de políticas públicas.

Pautada na Constituição, a Política Nacional de Habitação (PHN) estabeleceu condições de acesso à moradia digna à toda população, em especial às famílias de baixa renda e buscou a integração entre a política habitacional e a política de desenvolvimento urbano (BRASIL, 2004).

A PNH é composta por um conjunto de instrumentos criados para viabilizar sua implementação os quais integram o Sistema Nacional de Habitação (SNH): o Desenvolvimento Institucional, o Sistema de Informação, de Avaliação e Monitoramento e o Plano Nacional de Habitação. Esse conjunto possibilita a participação democrática, e a integração dos três níveis de governo e o envolvimento de outros agentes públicos e privados. Por outro lado, ela requer definições de regras que assegurem a articulação financeira de recursos onerosos e não onerosos necessários para implementá-la. A partir disto foram estabelecidos dois subsistemas: o de habitação de interesse social e o de habitação de mercado (BRASIL, 2004).

A PNH, desenvolvida pela Secretaria Nacional de Habitação, determina metas de médio e longo prazo, linhas de financiamento, programas de provisão, urbanização e modernização das habitações com prioridades e critérios de distribuição de acordo com o perfil do déficit habitacional. Ela é regida por princípios, objetivos gerais e diretrizes, que buscam garantir a inclusão social (BRASIL, 2004). 
Dentre os princípios que orientam a $\mathrm{PNH}$, foi destacado: universalizar o acesso à moradia digna; promover a urbanização; fortalecer o papel do Estado na gestão; tornar a problemática habitacional como prioridade nacional; democratizar o acesso à terra urbanizada; ampliar a produtividade melhorando a qualidade; incentivar a geração de empregos e renda. Já as diretrizes têm como direcionamento o desenvolvimento institucional, a mobilização de recursos, a identificação da demanda e gestão de subsídios, a qualidade e produtividade habitacional, o sistema de informação, avaliação e monitoramento da habitação, a urbanização de assentamentos precários e a produção da habitação.

No tocante à integração da política habitacional, por meio dos contratos de financiamento habitacional com desequilíbrio financeiro, no âmbito do Sistema Financeiro de Habitação, o Ministério das Cidades do Brasil afirma:

\footnotetext{
O Sistema Nacional de Habitação (SNH) é composto por uma instância de gestão e controle, articulada e integrada pelo Ministério das Cidades, pelo Conselho das Cidades, pelo Conselho Gestor do Fundo Nacional de Habitação de Interesse Social, pelos Conselhos Estaduais, do Distrito Federal e Municipais pelo Fundo Nacional de Habitação de Interesse Social (FNHIS), e pelos Fundos Estaduais e Municipais de Habitação de Interesse Social (FEHIS e FMHIS). Integram, ainda, o Sistema Nacional de Habitação uma rede de agentes Financeiros, promotores e Técnicos envolvidos na implementação da Política Nacional de Habitação (BRASIL, 2004, p. 52).
}

O Sistema Nacional de Habitação (SNH) tem dois subsistemas: o de Habitação de Interesse Social (SHIS) e o de Habitação de Mercado (SHM). O SHIS busca garantir que os recursos públicos se destinem com exclusividade à população mais carente que reflete o maior déficit habitacional brasileiro. O SHM visa a reorganizar o mercado privado, facilitando a promoção imobiliária (BRASIL, 2004). Ambos, a fim de atender às demandas habitacionais, levam em conta as diversas regiões do Brasil. Para tanto o custo de produção e o poder de pagamento são definidos pelo desenvolvimento regional e pelo poder aquisitivo das famílias beneficiadas, possibilitando a universalização proposta pela política (BRASIL, 2004).

A Política Nacional de Habitação (PNH) potencializa programas e ações nos três níveis de governo, incorporando os recursos financeiros, e outros recursos para auxiliar na eficiência e na efetividade de intervenção e na qualidade do projeto. Para implementá-la, a União, os estados, o Distrito Federal e os municípios deverão dispor de recursos suficientes em seus orçamentos e, junto com outras fontes, proporcionar as condições estabelecidas. Logo, a responsabilidade de seu cumprimento é de todos os agentes nela envolvidos. 
Ao Ministério das Cidades compete coordenar, elaborar, estimular e dar apoio aos demais órgãos na elaboração dos planos estaduais e municipais - necessária integração com os sujeitos sociais, pois, quanto maior a participação democrática no processo de construção, mais forte será sua execução (BRASIL, 2004). Nesse sentido, o próprio Caderno do Ministério das Cidades do Brasil afirma,

Projeto de Lei 2710/92, que trata da criação do Fundo Nacional de Habitação de Interesse Social, foi aprovado na Câmara dos Deputados, por meio da subemenda substituída global em 03 de junho de 2004. O referido projeto de Lei apresentado como primeiro projeto de iniciativa popular é fruto de manifestações e das grandes mobilizações dos Movimentos Populares de Moradia junto com o Movimento Nacional da Reforma Urbana (BRASIL, 2004).

A PNH também propõe contribuição nos investimentos privados no sentido de atender à demanda e às condições de mercado, por meio do Subsistema de Habitação de Mercado (SHM), o qual visa reorganizar o mercado privado de habitação, ampliando a captação de recursos e estimulando a inclusão, o que facilita a promoção imobiliária (BRASIL, 2004).

O agente operacionalizador do Fundo Nacional de Habitação é a Caixa Econômica Federal (CEF), que, dispondo dos recursos do Fundo Nacional de Habitação de Interesse Social (FNHIS), realiza as transferências, bem como define os procedimentos operacionais necessários, adotando os critérios elaborados pelo conselho gestor e pelo Ministério das Cidades. A CEF é analista das condições de aquisição do beneficiário e dos processos para aquisição, de modo a assegurar que sejam respeitados os princípios da PNH. Isso garante que os recursos contemplem as faixas de rendas, os programas e as modalidades exigidas nas demandas prioritárias. É, ao mesmo tempo, o principal banco federal captador da poupança popular e operacionalizador do SFHM (BRASIL, 2004). Embora o Ministério das Cidades seja responsável, por gerir a política habitacional, cabem à CEF as decisões e o acompanhamento aos empreendimentos, bem como influência no desenvolvimento urbano, uma vez que é responsável pela construção das habitações de interesse social.

O Banco Central do Brasil, por sua vez é responsável por fiscalizar as entidades financeiras que integram o SFH, em consonância com as diretrizes da PNH e articulado ao Ministério das Cidades (BRASIL, 2004).

O governo Lula demostrou empenho na resolução do problema da habitação, ao criar condições para moradia. Bonduki (2009 apud VERAS, 2014, p. 81) afirma: 
[...] foi visível o empenho do governo Lula no intuito de criar condições para viabilizar uma nova política urbana e habitacional no país. No entanto, ressalva a fragilidade institucional do Ministério das Cidades como um dos obstáculos, já que a CEF sendo a principal executora das Políticas Nacionais de Habitação, está subordinada ao Ministério da Fazenda.

Os municípios têm papel importantíssimo na implementação de habitação de interesse social (HIS), na busca de alternativas para melhorar a qualidade de vida nos grandes centros urbanos, onde está a maior parte da população brasileira, para isso o governo atribui aos municípios a implementação da HIS (VERAS, 2014).

$O$ Estatuto das cidades regulamenta os instrumentos legais para que as prefeituras atuem, de forma administrativa, na formulação da política de habitação. Ele destaca a importância dos municípios como protagonistas, ou seja, principais responsáveis pela formulação, implementação e avaliação da sua política urbana, em consonância com o estabelecido no plano diretor, que assegura a garantia do benefício a todas as cidades e a justa distribuição dos bônus e ônus do processo de urbanização (VERAS, 2014). Assim, compete às prefeituras providenciar o cadastro único e a inserção social das famílias no programa Minha Casa Minha Vida (PMCMV); identificar as áreas de interesse social; realizar os cadastros; analisar os dados; verificar a realidade social e solicitar as moradias - processo que constitui o primeiro passo para as famílias de baixa renda participarem do programa.

No processo de seleção dos beneficiários, há critérios a serem seguidos: aos beneficiários não podem ter outro domicílio no município; não terem sido beneficiados pelo programa; devem apresentar comprovação de renda conforme as exigências do programa.

Frente ao exposto, é essencial a gestão municipal desenvolver, com qualidade, as ações diretamente ligadas à sua prefeitura, ou seja, preparar a equipe técnica com capacitações direcionadas para ações do programa, o que possibilita o sucesso da política de habitação de interesse social.

\section{Caracterização do município de Cajazeiras - PB}

Cajazeiras (PB) é uma cidade cujo crescimento econômico está diretamente relacionado ao comércio e à educação, atividades que estimulam o processo urbano e imobiliário daquela região. Esse cenário desenvolvimentista tem atraído pessoas em busca de trabalho e de melhores condições de vida - fluxo migratório que, em grande escala e 
velocidade, traz alguns problemas, dentre os quais a falta de moradia. Mas, ao mesmo tempo, tal situação aquece o setor imobiliário (ANTONIO, 2014).

O aglomerado urbano percorreu um longo caminho até se elevar a cidade de Cajazeiras: constituiu um número mínimo de habitantes; construiu meios para o atendimento à saúde da população; criou escolas; abriu avenidas; construiu espaços de lazer etc. A prefeitura atuou no sentido de proporcionar ações que viabilizassem as atividades da população e atendessem aos setores ligados à qualidade de vida social. Em outras palavras, criou espaço para o desenvolvimento dos aspectos político, econômico e social.

Segundo Silva Neto (2015), como toda cidade em desenvolvimento, Cajazeiras vem tornando-se muito atrativa para pessoas a busca de trabalho e condições de vida. Inclusive, muitas pessoas migram do campo para cidade à procura de meios de sobrevivência. Esses dois fatores têm contribuído para o considerável aumento populacional.

Destaque em relação aos outros municípios sertanejos pelas características socioeconômicas, Cajazeiras é conhecida como cidade que ensinou a Paraíba a ler e como berço da cultura paraibana. Tanto que, nos dias atuais, constitui-se como polo de educação: dispõe de faculdades privadas, uma universidade pública e duas escolas técnicas. Por outro lado, embora inserida no polígono da seca, ela cresce, gerando desenvolvimento urbano considerável.

\section{O Conjunto Habitacional Recreio e os marcos referenciais na certificação da política}

De acordo com os documentos acessados na prefeitura municipal: o Memorial Descritível, Carta de Habite-se e o termo de Cooperação e Parceria no setor de habitação no ano de 2017, o Conjunto Habitacional Recreio está organizado em 3 quadras: a quadra 17, a 18 e a 20. A 17 subdivide-se em 43 lotes medindo 7.688,50 $\mathrm{m}^{2}$; a quadra 18 subdivide-se em 21 lotes medindo 5.304,00 $\mathrm{m}^{2}$ e a quadra 20 que subdivide-se em 36 lotes medindo 8.209,50 $\mathrm{m}^{2}$.

O loteamento tem 4 ruas: a via projetada 11, a via projetada 12, a via projetada 14 e a via coletora 2. A área verde, com $1.700,00 \mathrm{~m}^{2}$, está situada ao leste da quadra 17 e tem como acesso à via coletora 2 e as vias projetadas 11 e 12. Em síntese, o loteamento soma uma área total de $21.202,00 \mathrm{~m}^{2}$, a qual corresponde a 67,91\%; a área de arruamento corresponde a 26,64\%. A área total do loteamento é $31.222,00 \mathrm{~m}^{2}$. Consta entre a documentação, declaração devidamente assinada pelo gestor que a prefeitura possui 
Estrutura Administrativa, Operacional e Técnica para execução do projeto, no entanto não há nas proximidades escolas, bancos ou agências de correios, apesar do sistema de água, iluminação e pavimentação está concluído, no entanto, foi encontrado dificuldade na mobilidade urbana dos moradores (CAJAZEIRAS, 2004).

Para a efetivação do programa habitacional do referido loteamento se faz indispensável uma série de documentos que envolvem a instituição financeira, o poder público parceiro e seus beneficiários, entre eles destacam-se os que se teve acesso durante a pesquisa documental na Secretaria de Planejamento no setor de habitação da Prefeitura Municipal de Cajazeira - PB.

\title{
Carta de "Habite-se"
}

Carta de "Habite-se" - documento que atesta ter sido a construção de moradias feitas dentro das normas e da legislação local - é elaborada depois de fiscalização técnica. Apesar de não atestar segurança nem qualidade, comprova a execução da obra de acordo com o projeto,

\begin{abstract}
Certifica-se no Habite-se, documento que referencia através de vistoria realizada no local pelo serviço de fiscalização, que as 100 unidades de residências construídas no Loteamento Recreio, bairro Pio X, localizado na zona norte de Cajazeiras - PB, estão aprovadas, pois foram construídas de acordo com a legislação vigente, podendo ser utilizado para o fim a que se destina a habitação para população de baixa renda (PREFEITURA MUNICIPAL DE CAJAZEIRAS, 2006).
\end{abstract}

\section{Termo de Cooperação e Parceria}

O termo de cooperação e parceria é o documento formal utilizado para se estabelecer a parceria. Ele descreve a participação e a responsabilidade da Prefeitura Municipal de Cajazeiras e da Caixa Econômica Federal, como os interesses comuns, as obrigações e o propósito. O documento difere do convênio, pois não há possibilidade de os recursos serem transferidos para outro fim. Firma-se, por meio dele, que, de fato, houve o acordo cooperativo para viabilizar o Programa de Subsídio à Habitação de Interesse social, conjugado com o Programa Carta de Crédito FGTS (CAJAZEIRAS, 2004).

$\mathrm{Na}$ verdade, o conjunto em foco transformou-se em bairro: no entorno, da estrutura original, cresceram outros aglomerados habitacionais; está todo pavimentado e, aparentemente, com o sistema de saneamento básico concluído; a maioria das casas já estão reformadas com muros e jardins. É um bairro simples, bonito e acolhedor, onde 
encontrou-se muitos estabelecimentos comerciais, além de uma praça localizada no centro do conjunto. No momento da pesquisa, as ruas estavam limpas e com rondas de viaturas policiais militares. Entretanto, como o referido bairro fica longe do centro, três quilômetros, não há transporte urbano à disposição dos moradores, apesar de organizados em associação e das reuniões periódicas.

Tudo parecia normal quanto aos princípios norteadores daquelas construções. Contudo, à medida que se foi aprofundando a pesquisa, diferentes realidades chamaram a atenção. De imediato, percebeu-se que a nomenclatura do loteamento nos documentos existentes na prefeitura e no contrato com a CEF é Conjunto Habitacional Recreio, mas os moradores o conhecem como Conjunto Ronaldo Cunha Lima. Dado que trouxe inquietação e levou a buscar a resposta com os moradores, no sentido de entender o porquê das distintas denominações. Um deles assim nos respondeu:

\begin{abstract}
Essas casas do Conjunto Habitacional conhecido como Ronaldo da Cunha Lima têm um diferencial dos outros conjuntos da cidade, porque esse foi um financiamento da Caixa Econômica. A prefeitura entrou como avalista dos moradores, foram 100 famílias, foram beneficiadas. Não é da CEAP, não foi um programa da CEAP, foi um programa da Caixa Econômica Federal, então foram 100 residências. A princípio, $O$ nome do conjunto no papel era Deputado Estadual João Bosco Braga Barreto, mas com o passar do tempo, mudaram para Conjunto Ronaldo da Cunha Lima. Até na época, o Ronaldo nem podia ser homenageado, que ainda estava vivo. Ele que veio pra inauguração e tudo. Então, o conjunto é conhecido Ronaldo da Cunha Lima, mas o nome em lei era Deputado João Bosco Braga Barreto. Uma certa época, eu tomei conhecimento na prefeitura dessa questão do conjunto é Recreio né, seria toda essa área abrangente, seria uma área bem maior no caso. Mas a gente, todo mundo, conhece como Conjunto Ronaldo da Cunha Lima [BENEFICIÁRIO 1].
\end{abstract}

Ao longo da pesquisa, percebeu-se que os moradores desconheciam o nome documental do conjunto e que a gestão responsável pela execução de programa usou uma situação confusa para fins desconhecidos e fora das normas, já que uma pessoa em vida não pode ser homenageada dessa forma. Mas o fato é que em parte, isso foi alcançado, pois todos os moradores da cidade de Cajazeiras nomeiam, o conjunto em foco, como sendo Conjunto do Ronaldo Cunha Lima. Além do não esclarecimento, de alguma forma foi marcado como homenagem e sempre será associado a um favor político e não a um direito garantido.

\title{
A operacionalização da Política Nacional de Habitação no Conjunto Habitacional Recreio (Conjunto Ronaldo Cunha Lima): Diretrizes e normas da construção
}


De acordo com o termo de cooperação e parceria entre a CEF e a Prefeitura Municipal de Cajazeiras (PB), foram disponibilizadas as condições para a implementação do programa de subsídio à habitação de interesse social (HIS). As normas foram definidas pela portaria 231 de 04 junho de 2004 interministerial do Ministério da Fazenda e Ministério das Cidades, segundo a qual se concedeu aos beneficiários a aquisição e ou produção de unidades habitacionais de interesse social que atendessem aos padrões mínimos de salubridade, segurança e habitabilidade. Quanto aos recursos, provieram de linhas de financiamento do FGTS, dos subsídios do programa do Subsistema Habitação de Interesse Social e da contrapartida do poder público, a prefeitura municipal um montante de 300 mil reais.

Frente ao exposto, coube à CEF divulgar as informações necessárias para implantação dos programas, conforme o termo de cooperação acima citado; prestar os esclarecimentos necessários ao poder público; exigir a comprovação da documentação por parte do munícipio referente à Lei de Responsabilidade Fiscal; receber e analisar a documentação dos beneficiários; atestar o cumprimento do cronograma físico-financeiro e repassar o subsídio concedido.

À Prefeitura Municipal de Cajazeiras coube apresentar as leis e diretrizes adequadas ao processo de parceria com o referido programa; expor os projetos arquitetônicos e de infraestrutura; desenvolver as atividades de planejamento que favorecessem à implementação das moradias; regularizar os documentos necessários; organizar os grupos; fazer o acompanhamento das contratações e viabilizar a execução do projeto; organizar o processo de inscrição, seleção e classificação dos beneficiários e realizar o projeto técnicosocial (BRASIL, 2007). Entretanto, isso está só nos documentos, não na execução, segundo a fala do beneficiário:

Sim mas, como eu tinha falado, as 100 casas do Ronaldo foi um projeto da Caixa Econômica Federal. A prefeitura doou o terreno e a Caixa Econômica construiu. A prefeitura entrou como nosso avalista, o avalista dos 100 moradores que comprovasse baixa renda. Depois, no ato de entrega das nossas casas o governo federal já mandou a notícia que tinha sido perdoado a dívida. Nos tinha uma questão contratual a cumprir dos cinco anos, que seria o contrato, não poderíamos concorrer a uma nova casa. Passados os cinco anos, a caixa nos mandou uma correspondência dizendo que estava quitado, que nossa dívida estava toda quitada, que a gente já podia receber o documento de quitação de débito das casas. Esse documento de quitação de débito das casas só viemos receber no ano de 2015. Foi quitado em 2009, mas depois de muita briga dos moradores, depois de muita cobranças, nós em 2015 recebemos o documento de quitação das casas, foi entregue ali, na praça, pela prefeita Denise. Os moradores, quando se dirigiram 
para o cartório pra escriturarem suas residências, lá é comprovado que temos uma casa quitada pela Caixa Econômica, mas não temos um terreno, porque o terreno que foi conferido as 100 casas ainda não foi... é não foi feito o desmembramento dos lotes. Então, nós temos 100 casas construídas dentro de um só terreno. Então, nenhum morador do Ronaldo da Cunha Lima consegue escriturar suas casas. Isso dificulta a vida dos moradores em que, pra alugar uma casa, o morador tem medo de alugar. E já tivemos problema na justiça do inquilino querer tomar: ora, você não tem casa, vou tomar. A maioria das pessoas que compraram as casas vivem com medo, porque compram uma casa, e o documento ainda está no nome do anterior. As vezes, a casa é do quarto, cinco comprador. E ninguém consegue escriturar essas casas [BENEFICIÁRIO 1].

De acordo com essa fala, percebeu-se que parte das responsabilidades do município ficou a desejar, pois os beneficiários não conseguem o registro legal de sua habitação. Inseguros e constrangidos, não conseguem compreender nem explicar se de fato realmente são proprietários das casas.

\section{Perfil dos entrevistados}

A partir da pesquisa foi identificado os moradores do Conjunto Habitacional Recreio, na questão de gênero: são mulheres na faixa etária entre 40 e 50 anos. Dessas mulheres entrevistadas, 08 estão na condição de provedoras, que se desdobram com os afazeres domésticos e nos cuidados de filhos e netos, para enfrentar as despesas da casa.

Entre os serviços realizados por elas como meio de suprir as necessidades da família, que não é numerosa, foi constatado: diárias em diversas frentes de trabalho, como venda de pipoca e picolé nas próprias residências. Identificou-se ainda a partir do levantamento, que $60 \%$ das famílias a fonte de renda advém do Programa de Transferência de Renda - bolsa - família e ajuda comunitária. Também cuidam dos netos.

A maioria das residências abriga apenas um núcleo familiar, mas foi identificado duas famílias convivendo na mesma habitação. Quanto aos entrevistados, foram selecionadas 8 mulheres e 2 homens. No que se refere à escolaridade, apenas 2 beneficiários têm o segundo grau completo; 2 são analfabetos e sequer assinam o nome; o restante não concluiu o ensino fundamental, ou seja, de 1으 a 4 으 série do fundamental séries iniciais.

\section{Perspectiva da Renda}

Segundo o Caderno do Ministério das Cidades (BRASIL, 2004), a elaboração e implementação da PNH devem ser pautadas em princípios e ter como meta principal 
garantir à população de baixa renda o acesso à moradia digna. Ao serem questionados sobre a renda familiar, a maioria afirmou que dispunha de um salário mínimo, embora de fontes diversas, conforme observado nestes depoimentos:

Eu tenho um salário da minha filha, que ela é especial. Gasto muito com medicamento com ela; ela tem síndrome de Down, sequela, paralisia no braço, na mão, na perna. Tem dia que ela não anda nem direito [BENEFICIÁRIO 2].

Só o bolsa-família, e também esse ano eu ganhando o que o povo tão me dando [BENEFICIÁRIO 3].

Eu tô até desempregado. A mulher é que trabalha, ganha nas casas de família [BENEFICIÁRIO 4].

Conforme observado em relação à renda, os beneficiários se enquadravam nas diretrizes da PNH. Questionados sobre ter membros da família incluídos em programa social do governo federal, destacaram as seguintes falas:

\footnotetext{
Meu neto nunca conseguiu o bolsa-família, porque meu marido era aposentado, tu acha? Eu me aposentei há pouco tempo, ai ele quem era, aí ele era funcionário no causo, antes de se aposenta. Aí meu neto estudava e nunca ganhou nada do governo, tu acha? Só porque o avô era aposentado. Crio meu neto pela guarda do juiz e ele nunca ganhou nada. E ele não trabalha, ainda tá só estudando [BENEFICIÁRIO 5].
}

Tem. Eu sou... eu recebo um benefício social, de uma cirurgia que fiz no coração [BENEFICIÁRIO 6].

Tem o bolsa-escola, mas os meninos são tudo de maior, não recebe, só a menina que recebe [BENEFICIÁRIO 4].

Não, nenhum, nem emprego eles têm; estão tudo desempregado [BENEFICIÁRIO 2].

Nas respostas, evidencia-se que nem todos estavam incluídos em programas de transferência de renda do governo federal.

Posteriormente foi questionado sobre a suficiência da renda familiar para atender às necessidades básicas de todos, sendo constatado que passam por privações, inclusive os participantes dos programas de transferência de renda do governo federal, conforme observado abaixo:

É não, [...], eu passo precisão, [...], passo precisão. Eu não posso mais trabalhar com problema de saúde que eu tenho, tem muita coisa, eu tenho problema de pressão alta, bronquite alérgico, eu vivo no medicamento direto. [BENEFICIÁRIO 2]. 
Quando eu recebo o bolsa-família só... 200 conto pra eu comprar de tudo e ainda pagar água e luz. Dá não [BENEFICIÁRIO 3].

Dá não, porque só o comer, se nós for comer, a doença nós tem de diabete e tudo. Ele é pressão, avc, menino!!!! Ele compra mais de 300 só de remédio por mês, pros olhos, pra circulação na cabeça, só ele [BENEFICIÁRIO 5].

Esses depoimentos revelam situações de miséria, fome, doença, ausência de emprego e de renda e, em muitos casos, exclusão dos programas sociais.

\section{Características das Moradias}

Para Veras (2014), o termo Habitação de Interesse Social (HIS) significa encontrar soluções de moradias para a população de baixa renda, foi implantado com a criação do Banco Nacional de Habitação (BNH) e permanece nos dias atuais. Partindo do pressuposto de que uma das necessidades básicas do ser humano é proteção e abrigo, a moradia tornase fundamental para as pessoas, não apenas como um teto sobre sua cabeça mas, também como direito constitucional garantido,

\footnotetext{
Segundo o Comitê dos Direitos Humanos o direito à habitação não deveria ser interpretado em sentido estreito ou restrito que o equipara com o abrigo provido meramente de um teto sobre a cabeça dos indivíduos, ou julga o abrigo, exclusivamente, como uma mercadoria. Diferentemente, isso deveria ser visto mais propriamente como um direito a viver, onde quer que seja, com segurança, paz e dignidade (BRASIL, 2013, p. 34).
}

Hoje, a maioria das casas do conjunto em estudo está diferente do padrão estabelecido pelo programa, boa parte dos moradores não são os beneficiários inicialmente comtemplados. Por outro lado, foram encontrados beneficiários que participaram desde o início. A um desses indagou-se a respeito da estrutura física da casa,

[...] logo quando eu recebi essa casa aqui, ela completamente era cimento, o cimento se desmanchava todinho, não tinha nada. As paredes você não podia botar um armador que caía. Pouquinho um mês e 15 dias, quase 2 meses que eu estava na minha casa, as paredes começou se rachar e caindo os rebocos tudinho. E disse que gastou 7 mil nessa casa, mas o contrato que a gente tem era pra ter gastado 17 mil reais; 17 mil, e não foi gasto. E os banheiro, tudo caindo, tudo fulozado, os canos tudo caindo, intupido, as fossas tudo fedendo. Foi preciso eu fazer outra. E as portas, tudo aberta dando cupim, não tinha que prestasse. Era pra ter recebido as casas com área de serviço pra trabalhar e uma pia do lado de fora e não tinha nada disso [momento em que interrompo e faço novamente a pergunta de número 6]. Quatro, dois quartos e um banheiro. Aí eu trabalhei 10 anos e fui juntando um dinheirinho de 100 e de 50, dez anos, ainda juntei um dinheirinho e fiz essa reforma nela. Ainda hoje eu tô pagando ainda. Eu fiz uma conta de 23 mil reais pra eu ajeitar essa casa todinha. Tá com 5 anos que venho pagando... Não, a caixa não era 
alvenaria era de plástico. Água muito quente que todo mundo tomava banho adoecia. Foi um problema de saúde que eu apanhei, foi desse jeito: aqui não era calçado, era uma poeira que não tinha cristão que aguentasse. A gente já morou bem 8 anos, bem 6 anos na terra, na terra, na lama aí com o tempo. Quando calçaram aqui foi que melhorou a infraestrutura aqui [BENEFICIÁRIO 2].

Segundo alguns documentos, as unidades apresentam as seguintes características: habitação unifamiliar tipo popular, composta por uma sala, 2 dormitórios, 1 banheiro social, 1 cozinha, 1 área de serviço e 1 WC em um terreno com dimensão de 8 metros de frente por 21 metros de fundo. No entanto, foi constatado diferentes modificações, como acréscimo de murada e cômodos. Talvez porque, originalmente, sendo os cômodos muito pequenos, não comportariam, com certo conforto uma família pequena. Embora a maioria afirmasse que, em sua casa residia uma única família, não verdade, observou-se a presença até dos netos.

[...] é muito pequena, não tem nenhum conforto pra uma família viver. Mesmo assim, agradeço a Deus por ter recebido e fomos vivendo dentro até chegar o momento que deu pra fazer uma coisinha a mais pra aumentar [BENEFICIÁRIO 5].

Tem esses dois quartos, olha como o quartinho é vem ver. Tu num olha, nada, pra tu olhar por dentro. Esse aqui é meu marido. Olha a casa, tá vendo? Olha o muro, o tanto de terreno. Aqui, se não fechar, o comer azeda. Tá vendo desse tanto de muro, nem isso aqui ninguém não fez, aqui eu posso preparar pra eu lavar prato, pra eu lavar roupa... Só não tem como construir, porque só o aterro ei? E o predeiro, que é caro, tem não, nessa murada pra nos fazer que os ladrão tava subindo, era feira essa pra baixo. Aí os ladrão tava subindo, aí eu arrudiei todinho de novo, entendeu? A gente fez empréstimo... É não, pra gente doente, né? ... É confortável, porque é pra sadio; pra nós que somos é doente, não é não, você veja aí como é [BENEFICIÁRIO 7].

Pelo exposto, pode-se inferir que o conjunto em foco dispõe de espaço externo bastante amplo, mas a moradia deixa a desejar. Como o morador é de baixa renda, tem dificuldade de reorganizá-la. Assim, com muito sacrifício, alguns conseguiram fazer modificações na estrutura das residências. A propósito, a estrutura física da moradia é de extrema importância para estabelecer o nível de conforto e qualidade de vida. Faz parte do binômio da lógica da habitação de interesse social quantidade e qualidade, foco das diret rizes que regem a $\mathrm{PNH}$, fatores que precisam andar de mãos dadas. A área total de $168 \mathrm{~m}^{2}$, mas apenas $32,32 \mathrm{~m}^{2}$ de área coberta por casa unidade residencial.

\section{Cadastro das famílias para inserção social}

De acordo com Veras (2014), a indicação da área para a construção das HIS compete à prefeitura, que deve identifica-la, mapeá-la, cadastrar as famílias no Cadastro 
Único, analisar seus dados e real necessidades, principalmente, constatar a situação socioeconômica destas. Como existem critérios para a inserção das famílias contempláveis, são necessárias ações de técnicos municipais para que a seleção dos beneficiários seja justa.

Entre os principais critérios, destacam-se: comprovar vínculo domiciliar por determinado tempo, com o executor do programa, isto é, com a prefeitura municipal; não possuir outro imóvel de moradia; não ser responsável por outra família beneficiada em outro programa de habitação; principalmente, pertencer ao segmento de baixa renda.

Os técnicos municipais precisam visitar as áreas de moradia dos futuros beneficiários para verificação do cadastro e ações específicas do trabalho social. Essa é uma regra obrigatória e de responsabilidade exclusiva do município, pois o controle e o acompanhamento são fundamentais para as famílias beneficiadas nas etapas pré e pós-obra A propósito, o trabalho social engloba um conjunto de ações destinadas à melhoria na qualidade de vida e na nova moradia - acompanhamento que visa à mobilização, à organização e ao fortalecimento social (VERAS, 2014).

Os beneficiários, quando indagados sobre o processo de seleção e a forma de terem tomado conhecimento do programa, afirmaram:

Pra conseguir as casas, eu tomei conhecimento na mídia. O pessoal falava que ia ter a distribuição, entrega dessas casas. Me dirigi à promoção social e fiz meu cadastro [BENEFICIÁRIO 1].

[...] eu fiquei sabendo no primeiro governo de Carlos Antônio. A gente fez a escritura, na época o secretario era Zé Filho. A gente fez a inscrição com Gorete, que trabalhava com ... deixa eu lembrar o nome dela... Fátima de Neném de Zé Neto. E quem fazia a reunião com a gente era Gorete. Olha, muita gente ia pra reunião de manhã e à tarde. Era uma equipe e era 3 vezes no mês. Eu pelo menos nunca falhei uma reunião. Sempre as atas da gente era assinada pela Caixa Econômica, e a gente foi mais prejudicada, demorou mais entregar. A respeito disso, as pessoas que receberam essas casas não comparecia nem a metade: era 100 famílias; se parecia 20 famílias, era muito. Aqui, depois que foram entregue, se mora 20 dono, mora muito, que tudo foi vendida (Momento em que interrompo $e$ refaço a pergunta de número 07). Na própria prefeitura que dr. Carlos que me avisou, porque sabia que eu precisava muito, que eu morava em casa alugada, lavava roupa e engomava pra poder sobreviver, não tinha marido, criava meus filhos só, deixava eles 3 sozinhos trancados dentro de casa pra poder trabalhar, porque eu não tinha quem me ajudasse. Eu criava meus filhos lavando $e$ engomando, por isso eu vivo doente assim [BENEFICIÁRIO 3].

Como eu já Ihe falei, eu acho que, na época, foi pelo rádio. Uma amiga minha me avisou e eu fui e fiz a inscrição, e fui chamada, avisada pelo rádio também pra assistir as reunião, na época, na biblioteca... Precisava, eu nem lembro mais quanto tempo foi de reunião, mas acho que foi uns três anos assistindo reunião [BENEFICIÁRIO 5]. 
Nesse depoimento percebeu-se que os beneficiários tomaram conhecimento de que haveria distribuição de moradias para famílias de baixa renda por meio do rádio e de outras pessoas já cadastradas na Secretaria de Promoção Social, organização realizada por uma equipe de técnicos da prefeitura. Então informados, foram a busca dos benefícios, iniciando o processo de aquisição, percorrendo longo caminho até as moradias.

Percebe-se pelas falas que a condução do processo por parte dos técnicos da prefeitura deixou a desejar em razão da desproporcionalidade nas participações das reuniões ${ }^{1}$ e da demora de mais de três anos para saírem os resultados, e que criou um vácuo entre o disposto na lei e o processo de aplicabilidade do programa.

Essa realidade demonstrou que muitos pretendentes cansaram, desanimaram e se desestimularam, de modo que hoje só $20 \%$ dos beneficiários ocupam as habitações do programa. Portanto fica um campo aberto para novas investigações e estudos posteriores para explorar as verdadeiras razões que levaram $80 \%$ das pessoas contempladas com as moradias a abrir mão desse benefício, uma vez que não foram repassadas para outras pessoas necessitadas, e sim vendidas, trocadas ou alugadas.

\section{Considerações finais}

Destarte, este estudo evidenciou que o fato de o beneficiário estar no programa e receber a moradia não lhe garantem a satisfação nem o conforto da família, pois, além de o processo ser demorado, algumas exigências não foram observadas. Conforme os entrevistados, a moradia não atende ao padrão de qualidade e comodidade para as famílias, inclusive porque o espaço interno é desproporcional para os contemplados, principalmente, os acometidos de enfermidades. Ademais, embora a área não construída seja suficiente, a maioria das famílias não tem recursos para realizar as melhorias necessárias. Desse modo, quase ao término do trabalho, permanece a dúvida: houve falha no projeto ou a execução foi errada?

Foi analisado que vários pontos contidos na PNH não foram atendidos plenamente. Um exemplo fora à situação dos lotes em modalidades de produção individuais para unidades habitacionais: segundo os entrevistados, não foram desmembrados, o que os impede de obter a escritura individual, ou seja, a situação fundiária do empreendimento está ilegal. Outra situação identificada é que as residências do conjunto em questão não se

\footnotetext{
${ }^{1}$ (Beneficiária 3, ...alguns participavam de todas as reuniões; outros nunca estavam presentes). Informação colhida dos entrevistados durante processo de entrevista no ano de 2017.
} 
enquadram no conceito de moradia digna defendida pela Organização das Nações Unidas (ONU). A moradia digna precisa ser vista como um direito a viver em um lugar seguro, com paz e dignidade, que é composto por liberdade, garantias e proteção. Conforme a Comissão sobre Assentamentos Humanos e a Estratégia Global para Habitação para o ano 2000 afirmaram: "habitação adequada significa privacidade adequada, espaço adequado, segurança, iluminação e ventilação adequada, infraestrutura básica adequada e localização adequada em relação ao trabalho e facilidades básicas". O que se manifesta nos depoimentos dos beneficiários quanto à qualidade e ao conforto.

De outra parte percebe-se que faltou estímulo por parte dos técnicos no sentido de os beneficiários participarem nas principais etapas do projeto. Em relação à infraestrutura, o conjunto foi entregue sem pavimentação. Tudo isso sugere ausência de controle social e de transparência dos procedimentos decisórios. O que transgride as orientações da nova PHN no Conjunto Habitacional Recreio, na cidade de Cajazeiras.

Merecem destaque também os depoimentos dos entrevistados quanto à raridade dos primeiros beneficiários: a maioria já não é proprietário das residências - afinal, a apropriação correta dos bens e os serviços colocados à disposição dos beneficiários são normas prioritárias do programa. Assim, como tal propriedade é intransferível, o proprietário não pode ser beneficiado em programas habitacionais.

Por fim, embora tenha-se constatado falhas no processo de criação do Conjunto Habitacional Recreio, reafirma-se a importância da PHN. Destacou-se que o governo Lula tirou a referida política do campo da idealização para a efetivação. Porém, como é recente, ela requer reflexões e discussões, uma vez que se constitui campo vasto de produção de conhecimento e de intervenção prática para o assistente social.

É inegável que a proposta do Ministério das cidades tirava o vazio institucional existente entre o governo federal e as diversas instâncias em discursão acerca da política urbana. A estrutura do Ministério das Cidades propunha enfrentar os três principais problemas que afetavam diretamente os menos favorecidas, isto é, a moradia, o saneamento e as questões de transporte. $O$ atual governo extinguiu essa importante pasta, que foi criado com o intuito de combater as desigualdades sociais. O que observa-se na atualidade é um profundo retrocesso diante de conquista e diretos garantidos por meio das lutas travadas pelos movimentos sociais. A política de habitação que ainda precisava de 
mudanças para avançar e progredir, entra, atualmente, num processo de desmonte significativo e preocupante.

\section{Referências}

ANTONIO, José. Os avanços de cajazeiras no setor imobiliário. 2014. Disponível em: http://www.diariodosertao.com.br/coluna/os-avancos-de-cajazeiras-no-setor-imobiliario. Acesso em: 5 fev. 2017.

BONDUKI, Nabil. Política habitacional e inclusão social no Brasil: revisão histórica e novas perspectivas no governo Lula. Revista Eletrônica de Arquitetura e Urbanismo, São Paulo, n. 1, p. 71-104, set. 2008.

BRASIL. [Constituição (1988)]. Constituição da República Federativa do Brasil de 1988. Brasília, DF: Presidência da República, 1988. Disponível em:

http://www.planalto.gov.br/ccivil_03/constituicao/constituicao.htm. Acesso em: 5 fev. 2017.

BRASIL. Ministério das Cidades. Política nacional de habitação. Brasília: Ministério das Cidades, 2004. (Caderno 4).

BRASIL. MINISTÉRIO DAS CIDADES. Guia Básico dos Programas Habitacionais. Direito à Moradia [online]// Programa de habitação, 2007. Acesso em 24 de setembro de 2018. https://www.mdr.gov.br/images/stories/ArquivosSNH/ArquivosPDF/Publicacoes/Guia_Basic o_Programas.pdf

BRASIL. Ministério das Cidades. Secretaria Nacional de Habitação. Déficit habitacional no Brasil 2008. Brasília: Ministério das Cidades, 2011.

BRASIL. Secretaria de Direitos Humanos da Presidência da República. Por uma cultura de direitos humanos: direito à moradia adequada. Brasília: Coordenação Geral de Educação em SDH/PR, 2013.

CAJAZEIRAS. Prefeitura Municipal. História. 2004. Disponível em: http://cajazeiras.pb.gov.br/historia_do_municipio.php. Acesso em: 5 fev. 2017.

SANTOS, Angela Moulin S. Penalva; DUARTE, Santos Marino. Política habitacional no Brasil: uma nova abordagem para um velho problema. RFD - Revista da Faculdade de Direito da UERJ, Rio de Janeiro, v. 1, n. 18, 2010.

SILVA NETO, Alvino Pereira. Planejamento urbano e crescimento do município de Cajazeiras/PB De 1980 ATÉ 2015. 2015. Trabalho de Conclusão de Curso (Graduação em Geografia) - Universidade Federal de Campina Grande, Cajazeiras, 2015.

VERAS, Margaux Hildebrandt. O Programa Minha Casa Minha Vida e as repercussões na dinâmica socioespacial e sua inserção no contexto urbano na área conurbada de Florianópolis. 256 f. 2014. Dissertação (Mestrado em Urbanismo, História e Arquitetura da Cidade) - Universidade Federal de Santa Catarina, Florianópolis, 2014. 
Recebido em: 24/10/2018

Aceito em: 21/02/2020 